\title{
CircRNA-016901 silencing attenuates irradiation-induced injury in bone mesenchymal stem cells via regulating the miR-1249-5p/HIPK2 axis
}

\author{
XIANHUI WEN ${ }^{1,2^{*}}$, JUNHUA ZHANG $^{1 *}$, WENJUAN YANG $^{3}$, XINMIN NIE $^{4}$, \\ RONG GUI $^{1}$, DONGYONG SHAN ${ }^{5}$, RONG HUANG ${ }^{1}$ and HONGYU DENG ${ }^{6}$
}

\begin{abstract}
${ }^{1}$ Department of Blood Transfusion, The Third Xiangya Hospital of Central South University, Changsha, Hunan 410013;
${ }^{2}$ Department of Clinical Laboratory, The Affiliated Hospital of Guizhou Medical University, Guiyang, Guizhou 550004;

${ }^{3}$ Key Laboratory of Translational Radiation Oncology, Department of Radiation Oncology, The Affiliated Cancer Hospital of Xiangya School of Medicine, Central South University, Hunan Cancer Hospital, Changsha, Hunan 410013; Departments of ${ }^{4}$ Laboratory Medicine, and ${ }^{5}$ Oncology, The Third Xiangya Hospital of Central South University, Changsha, Hunan 410013; ${ }^{6}$ Department of Laboratory Medicine, Hunan Cancer Hospital and The Affiliated Cancer Hospital of Xiangya School of Medicine, Central South University, Changsha, Hunan 410013, P.R. China
\end{abstract}

Received November 20, 2019; Accepted August 19, 2020

DOI: 10.3892/etm.2021.9786

\begin{abstract}
Currently, bone marrow transplantation remains the basic treatment for various hematological tumors and irradiation is one of the most important pretreatment methods. However, irradiation pretreatment may result in damage to bone mesenchymal stem cells (BMSCs). The present study aimed to investigate the effect of circular RNA-016901 (circ-016901) on the injury of irradiation-induced BMSCs and the underlying mechanism. The expression levels of circ-016901, microRNA-1249-5p (miR-1249-5p) and homeodomain interacting protein kinase 2 (HIPK2) in irradiation-induced mouse BMSCs at various irradiation doses were detected via reverse transcription-quantitative PCR (RT-qPCR). The effect of circ-016901 on cell proliferation was examined using Cell Counting Kit-8 assays following silencing or overexpression of circ-016901. Cell apoptosis was detected by flow cytometry and caspase-3/7 activity. The expression of autophagy-related markers, including Beclin-1 and LC3-II/I, was detected at the
\end{abstract}

Correspondence to: Dr Junhua Zhang, Department of Blood Transfusion, The Third Xiangya Hospital of Central South University, 138 Tongzipo Road, Changsha, Hunan 410013, P.R. China E-mail: xy3zhangjunhua@csu.edu.cn

*Contributed equally

Abbreviations: TBI, total body irradiation; BMSCs, bone mesenchymal stem cells; circRNA, circular RNA; siRNA, small interfering RNA

Key words: circRNA-016901, irradiation, bone mesenchymal stem cells, autophagy, miRNA-1249-5p/HIPK2 axis
mRNA and protein levels by RT-qPCR and western blotting, respectively. Irradiation treatment upregulated the expression of circ-016901 and HIPK2 and downregulated miR-1249-5p expression. The expression levels of LC3-II/I and Beclin-1 in BMSCs were downregulated in a dose-dependent manner. Silencing of circ-016901 promoted proliferation of irradiationinduced BMSCs and attenuated irradiation-induced apoptosis. Moreover, silencing of circ-016901 elevated the expressions of LC3-II/I and Beclin-1 in irradiation-induced BMSCs. Similar results were obtained with miR-1249-5p overexpression and HIPK2 silencing. These results demonstrated that circ-016901 silencing attenuated injury in irradiation-induced mouse BMSCs by regulating the miR-1249-5p/HIPK2 axis, providing a novel target for future research on the mechanism of radiation resistance in BMSCs.

\section{Introduction}

The evolution of bones enhances an animal's ability to escape hazards and bone stem cells continuously produce bone cells to maintain bone homeostasis (1). The survival and aging of skeletal stem cells are regulated by numerous physiological factors $(2,3)$, including secreted class 3 semaphorin (2), parathyroid hormone (4), hypoxia-inducible factor $1 \alpha$ (5) and non-coding RNA $(6,7)$. The formation and maintenance of osteoblasts is associated with glutamine metabolism and pathological processes $(1,8)$, such as the development of leukemia (9) and hematologic malignancy (10). In clinical treatment, external stressors (including hypoxia and radiation) damage cells and trigger an immune response (11). Non-coding RNA mediates cellular immune responses against harmful stimuli $(12,13)$ and in bone marrow mesenchymal stem cells (BMSCs) (14).

Recently, research on the treatment of blood diseases at the molecular level has received widespread attention (15-17). 
BMSCs are a type of multipotent stem cell that participate in the formation of the bone marrow (BM) hematopoietic microenvironment (18), which is more tolerant to radiation than hematopoietic stem cells (19). BMSCs are important structural and functional components of hematopoietic recovery and reconstruction, following radiation injury (19). Prior to organ transplants, patients are subjected to total body irradiation (TBI) (20). Previous studies have demonstrated that patients who receive TBI to destroy infected tissues and cells prior to BM transplantation suffer damage to healthy BM cells, such as BM stromal cells (21-23). Furthermore, previous studies have reported that BMSC transplantations stimulate hematopoiesis, accelerate lymphocyte recovery and promote tissue repair $(24,25)$. However, in the early stage of transplantation, BMSCs may undergo a variety of adverse reactions, including oxidative stress, hypoxia and inflammatory reactions (26). Irradiation has been reported to promote homing of BMSCs following BMSC transplantation $(27,28)$. Moreover, irradiation promotes transplanted BMSCs to be implanted and induce the formation of new bone (29). Therefore, the relevant molecular mechanisms underlying irradiation-induced injury of BMSCs require investigation to discover novel strategies for irradiation injury.

Circular RNA (circRNA) is widely expressed in mammalian cells and is a type of non-coding endogenous RNA molecule that regulates gene expression (30). Numerous studies have demonstrated that circRNA may serve important roles in the progression of various diseases, including neurological disorders, diabetes and types of cancer (31-33), indicating that circRNAs may be an important biomarker for predicting disease progression and prognosis. A previous study has reported that the expression profiles of circRNAs in mouse BMSCs were significantly altered following irradiation (34). Additionally, the expression levels of circRNA-011235 and circRNA-016901 were significantly increased in mouse BMSCs following irradiation (34). However, whether circRNA-016901 influences irradiation-induced injury of BMSCs and associated molecular mechanisms remains unclear and requires further exploration.

MicroRNAs (miRNAs or miRs) are a class of noncoding small RNA molecules that are involved in various important physiological and pathological processes (35), such as asthma (36), brain aging (37) and prostate cancer (38). MiRNAs act mainly by complementarily pairing with the 3'-untranslated region (UTR) region of target gene mRNA (39) to degrade or inhibit its expression (40). Furthermore, miRNAs serve important regulatory functions for growth and development, and the occurrence and development of various diseases, which included ischemic heart disease and chronic lymphocytic leukemia (41). A previous study has demonstrated that miR-1249-5p expression is significantly increased in chronic intermittent hypoxia-treated mouse aortic endothelial cells and is closely associated with apoptosis and autophagy (42). As previously reported, miR-1249 inhibits cell proliferation, invasion, migration and epithelial-mesenchymal transition processes in colorectal cancer (43). Furthermore, microarray analysis revealed that miR-1249-5p was upregulated in types of cancer, including cardiac myxoma and colon cancer, indicating miR-1249-5p may serve a tumor-promoting function $(44,45)$. miR-1249-5p has been demonstrated to be activated in hepatocellular carcinoma and involved in the regu- lation of apoptosis (46). Increasing evidence has revealed that circRNAs bind to miRNAs to regulate miRNA function (47). Bioinformatics analysis demonstrated that circ-016901 contained a binding site for miR-1249-5p. However, the role of circ-016901 and miR-1249-5p in regulating irradiationinduced injury of BMSCs remains unclear.

Homeodomain-interacting protein kinase (HIPK) is a serine/threonine protein kinase located in the nucleus and the HIPK subfamily includes HIPK1, HIPK2 and HIPK3 (48). As a transcription factor, HIPK2 regulates cell differentiation, proliferation, angiogenesis and apoptosis and is associated with tumor development and progression (49-51). A recent study has reported that HIPK2 is a tumor suppressor gene that affects the biological characteristics of various tumors, including esophageal squamous cell carcinoma (52). Additionally, HIPK2 is a key regulator of renal fibrosis and is a serum marker (53). A previous study has demonstrated that HIPK2 activates p53 function under UV irradiation, thereby promoting apoptosis (54). Furthermore, HIPK2 has been predicted to be one of the candidate target genes for miR-1249-5p through TargetScan bioinformatics analysis. However, the function of the miR-1249-5p/HIPK2 axis in irradiation-induced injury of BMSCs and the potential molecular mechanisms remains to be elucidated.

The present study aimed to investigate the expression and potential role of circ-016901, miR-1249-5p and HIPK2 on autophagy and apoptosis in irradiation-induced injury of BMSCs, which may provide novel clinical targets to protect BMSCs from irradiation injury.

\section{Materials and methods}

BMSC isolation, culturing and identification. All animal procedures and euthanasia were reviewed by local government authorities in accordance with the local Animal Care Committee of Third XiangYa Hospital of Central South University (Hunan, China) in line with the Helsinki Declaration.

Adult male BALB/c mice (age, 8-10 weeks; weight, 18-25 g) were purchased from the laboratory animal center of the Third Xiangya Hospital of Central South University, Hunan, China. Mice were housed at $22 \pm 2^{\circ} \mathrm{C}$ at $40-60 \%$ humidity with 12-h light/dark cycles. Mice had free access to food and water. A total of $50 \%$ volume/min $\mathrm{CO}_{2}$ flow rate was used for euthanasia (55). When the volume of $\mathrm{CO}_{2}$ reached at $70 \%$, mice would lose consciousness (recumbency without muscle tone) within $30 \mathrm{sec}$, thus mice were euthanized using $\mathrm{CO}_{2}$ combined with cervical dislocation. This method avoided the effect of abnormal hypoxia on the experimental results. As all exogenous factors were identical when mice were sacrificed, the anomalous effects of cell autophagy and apoptosis caused by hypoxia on BMSCs can be excluded.

Tibias and femurs were surgically excised from mice and immersed in $75 \%$ ethanol solution at $25^{\circ} \mathrm{C}$ for a few seconds to disinfect the medullary cavity proximal to the end of the tibias and femurs which were touched by the scissors. Tibias and femurs were washed in $\alpha$ modification minimum essential medium ( $\alpha$-MEM) (cat. no. 36450; Stemcell Technologies, Inc.) supplemented with $10 \%$ FBS (cat. no. F2442; Sigma-Aldrich; Merck KGaA) and 5 U/ml 
Table I. Sequences and mass of all miRNA/siRNA in transfection.

Name

Sequence $\left(5^{\prime} \rightarrow 3^{\prime}\right)$

$\operatorname{Mass}(\mu \mathrm{g})$

circ-016901 siRNA

Scrambled siRNA negatice control

miR-1249-5p mimics

miRNA control mimics

HIPK2 siRNA

GGGCTGGTTCTTCTTCACATA
GTGCTTATCAGCCGGTTTCTA
UCCUCCCUCCCCUACCCGGUUCAAG
UUUGUACUACACAAAAGUACUG
GATCACTCCACCACGTAGACT

GGGCTGGTTCTTCTTCACATA

3.33

3.33

4

4

3.33

siRNA, small interfering RNA; miRNA, micro RNA; HIPK2, homeodomain-interacting protein kinase.

heparin (cat. no. BP2524100; Thermo Fisher Scientific, Inc.) and bone marrow was collected.

Cells were washed twice with heparin-free $\alpha$-MEM medium and seeded into petri dishes (seeding density, $2 \times 10^{6}$ cells $/ \mathrm{ml}$ ) after $24 \mathrm{~h}$ of bone marrow collection. Cells were washed three times with PBS three days later to remove unattached cells and cultured in DMEM medium (cat. no. 11965092; Thermo Fisher Scientific, Inc.) supplemented with 10\% FBS. Cells were cultured in an incubator at $37^{\circ} \mathrm{C}$ containing $5 \% \mathrm{CO}_{2}$ for $24 \mathrm{~h}$. At $80 \%$ confluence, BMSCs were digested with $0.25 \%$ trypsin (cat. no. MFCD00130286; Sigma-Aldrich; Merch $\mathrm{KGaA}$ ) at $37^{\circ} \mathrm{C}$ for $2 \mathrm{~min}$, adjusted to a density to $1 \times 10^{6}$ cells $/ \mathrm{ml}$, washed twice with PBS and centrifuged at $300 \mathrm{x}$ g for 5 min at $4^{\circ} \mathrm{C}$. FITC-labeled cluster of differentiation (CD) 34 (cat. no. 553733; BD Biosciences), CD45 (cat. no. 553080; BD Biosciences) and stem cell antigen 1 (Sca-1) (cat. no. ab25031; Abcam) mixed with CD90 (cat. no. 1740-02; SouthernBiotech) were added to the cell suspension and incubated for 15-25 min at $20-25^{\circ} \mathrm{C}$ in the dark. Following this, BMSCs were identified using flow cytometry (ZE5 Cell Analyzer; cat. no. 12004279; BioRad Laboratories, Inc.), data were analyzed using FlowJo software (version 10.0; FlowJo LLC).

Following identification via flow cytometry, positive cell ratios of CD34, CD45, Sca-1 and CD90 were 0.75, 0.96, 99.42 and $98.01 \%$, respectively, indicating that the majority of cells were CD34(-), CD45(-), Sca-1(+) and CD90(+). The identification and characteristics of BMSCs were based on the immunophenotype of mouse BMSCs (56). Isolated and identified cells were used for subsequent studies.

Irradiation treatment. Single cell suspensions of BMSCs (seeding density, $2 \times 10^{6}$ cells $/ \mathrm{ml}$ ) were plated into a $96-$ well culture dish until cells reached $80 \%$ confluence. Cells were divided into 4 groups and irradiated with 0 (control group), 2, 4 or 6 Gy for various time points of 6,12 and 24 h under room temperature conditions $\left(25^{\circ} \mathrm{C}\right)$ in the X-ray radiation field of a linear accelerator (2008 Synergy s/n 151765; Elekta) at a dose rate of $0.4 \mathrm{~Gy} / \mathrm{min}$ with a source target distance of $100 \mathrm{~cm}$.

Transfection. Cells in the logarithmic growth phase were transfected (seeding density, $1.5 \times 10^{5}$ cells $/ \mathrm{ml}$ ). Circ-016901 small interfering (si)RNA, miR-1249-5p mimics, HIPK2 siRNA or corresponding controls, scrambled siRNA (NC) or control mimics (all GenePharma, Inc.) were transfected into BMSCs using a Lipofectamine ${ }^{\circledR} 2000$ Transfection Reagent kit (cat. no. 11668030; Thermo Fisher Scientific, Inc.), according to the manufacturer's protocol. The sequences and mass of all miRNA/siRNA were listed in Table I. The transfection was performed at $37^{\circ} \mathrm{C}$ for $48 \mathrm{~h}$. At $24 \mathrm{~h}$ post-transfection, the transfection efficiency of siRNA and overexpression was detected using reverse transcription-quantitative PCR (RT-qPCR).

Dual-luciferase reporter assay. circ-016901 and HIPK2 were determined to contain binding sites for miR-1249-5p using the Starbase (version 2.0; http://starbase.sysu.edu.cn/index. php), TargetScan (release 7.2; http://www.targetscan.org/ vert_72/) and IntaRNA (version 2.0; http://rna.informatik.unifreiburg.de/IntaRNA/Input.jsp) databases. Subsequently, the miR-1249-5p mimics and control mimics were subcloned into the Renilla luciferase reporter vector psiCHECK-2 (Promega Corporation) according to the manufacturer's instructions. Circ-016901 and HIPK2 wild-type (WT) and mutant (MUT) Dual-luciferase reporter vectors were constructed and co-transfected with miR-1249-5p mimic or NC control using Lipofectamine $^{\circledR} 2000$ (cat. no. 11668030; Thermo Fisher Scientific, Inc.), according to the manufacturer's protocol. Following incubation for $48 \mathrm{~h}$ at $37^{\circ} \mathrm{C}$ in a $5 \% \mathrm{CO}_{2}$ incubator, cells were harvested and detected for luciferase activity using Dual-Luciferase ${ }^{\circledR}$ Reporter 1000 Assay system (Promega Corporation) and presented as the ratio of firefly to Renilla luciferase activity.

Cell Counting Kit (CCK)-8 assay. The cells treated with varying doses and times of irradiation were seeded at into 96-well plates (seeding density, $5 \times 10^{3}$ cells/well) and cultured in an incubator at $37^{\circ} \mathrm{C}$ containing $5 \% \mathrm{CO}_{2}$. Cell proliferation was measured at $0,24,48$ and $72 \mathrm{~h}$ following seeding using a CCK-8 Assay kit (cat. no. ab228554; Abcam) according to the manufacturer's protocol. Briefly, $10 \mu \mathrm{l}$ of CCK-8 solution was added to each well. Following incubation for $1 \mathrm{~h}$ at $37^{\circ} \mathrm{C}$ in a $5 \% \mathrm{CO}_{2}$ incubator, the absorbance (optical density, OD) of each well was measured using a microplate reader (BMG Labtech, $\mathrm{GmbH}$ ) at a wavelength of $450 \mathrm{~nm}$ and was used to calculate relative cell numbers over the ratio of absorbance from $\geq 3$ scopes.

Flow cytometry assay. Cells in each treatment group were supplemented with serum-free DMEM medium to induce apoptosis. Briefly, cells were digested with $0.25 \%$ trypsin at $37^{\circ} \mathrm{C}$ for $2 \mathrm{~min}$. to prepare a single cell suspension and washed twice with ice cold PBS. Cells were incubated with Annexin V-FITC (cat. no. ab14085; Abcam) for $10 \mathrm{~min}$ at 
room temperature $\left(25^{\circ} \mathrm{C}\right)$. Following this, the probe solution, $50 \mu \mathrm{g} / \mathrm{ml}$ propidium iodide (PI; cat. no. ab14083; Abcam) was added directly to the cell suspension. Cells were incubated for $30 \mathrm{~min}$ at room temperature in the dark prior to flow cytometry analysis. Subsequently, the cells were washed with fresh serum-free DMEM. The fluorescent intensity was detected via flow cytometry (ZE5 Cell Analyzer; cat. no. 12004279; Bio-Rad Laboratories, Inc.) and apoptosis rate was measured a by Annexin V-PI Apoptosis Detection kit (Abcam), according to the manufacturer's protocol. Data were analyzed using FlowJo software (version 10.0; FlowJo LLC).

Caspase-3/7 activity assay. Following transfection, $100 \mu \mathrm{l}$ of cell suspension was added to 96-well plates (seeding density, $1 \times 10^{6}$ cells $/ \mathrm{ml}$ ). Caspase-Glo reagent (cat. no. G8200; Promega Corporation) was added to each well, according to the 1:1 principle. Cells were gently centrifuged at $80-120 \times$ g at $4^{\circ} \mathrm{C}$ for $30 \mathrm{sec}$ and incubated for $2 \mathrm{~h}$ at room temperature. Incubated sample plates were then placed in a Veritas ${ }^{\mathrm{TM}}$ Microplate Luminometer (Promega Corporation) to detect the fluorescence value of each sample for data analysis.

RNA isolation and RT-qPCR. Total RNA was extracted from cells using TRIzol ${ }^{\circledR}$ reagent (cat. no. 15596026; Thermo Fisher Scientific, Inc.), according to the manufacturer's protocol. First-strand cDNA was synthesized via reverse transcription from total RNA using the HighCapacity cDNA Reverse Transcription kit (cat. no. 4368814; Thermo Fisher Scientific, Inc.), quality was determined using OD260/OD280 by NanoDrop ND-1000 instrument (Agilent Technologies, Inc.) and digested with Rnase R (cat. no. 19101; Qiagen China Co., Ltd.) to remove linear RNAs. qPCR was performed using SYBR-Green PCR Master Mix (cat. no. 4367660; Thermo Fisher Scientific, Inc.) on a ViiA 7 Real-time PCR system (cat. no. 4453545; Thermo Fisher Scientific, Inc.). Experiments were performed in triplicate. The thermocycling conditions used for qPCR were as follows: $50^{\circ} \mathrm{C}$ UNG activation step for $2 \mathrm{~min}$; denaturation for $30 \mathrm{sec}$ at $95^{\circ} \mathrm{C}$; followed by 40 cycles of denaturation for $5 \mathrm{sec}$ at $95^{\circ} \mathrm{C}$ and annealing for $30 \mathrm{sec}$ at $60^{\circ} \mathrm{C}$. GAPDH mRNA was used to normalize the expression levels of target genes. U6 was used for normalization of miR-1249-5p expression level. Relative mRNA expression levels were calculated using the $2^{-\Delta \Delta \mathrm{Cq}}$ method (57). Primer sequences used in the present study were as follows: circ016901 forward, 5'-ACAGCGCTAC ACTTGTTCCGA-3' and reverse, 5'-GACGATGCTA TCCAG GAGAGGT-3'; miR-1249-5p forward, 5'-GAGGAGGG AGGGGATG-3' and reverse, 5'-TCCAGTTTTTTTTT TTTTTTGAACTTG-3'; HIPK 2 forward, 5'-CTTCAGGAG CCATCGCCTAC-3' and reverse, 5'-CTGTTG TGCGGG AAGGTGTA-3'; light chain 3 (LC3) forward, 5'-ATGCCGTC CGAGAAG-3' and reverse, 5'-TTACACAG CCATTGCTG-3'; Beclin-1 forward, 5'-CGGA AT TCTATGGA AGGGTCTAA GACGTCC-3' and reverse, 5'-CGGGATCCTCATTTGTT ATAAAATTGTGAGGACA-3'; U6 forward, 5'-CTCGCTTC GGCAGCACA-3' and reverse, 5'-AACGCTTCACGAAT TTGCGT-3'; and GADPH forward, 5'-CACTGAGCAAG AGAGGCCCTAT-3' and reverse, 5'-GCAGCGAACTTTAT TGATGGTATT-3'.
Western blotting. Each group of cells was washed with PBS, centrifuged at $300 \mathrm{x}$ g at $4^{\circ} \mathrm{C}$ for $5 \mathrm{~min}$ and the supernatant was discarded. Cells were lysed on ice for 30 min using RIPA protein lysate (cat. no. ab7937; Abcam) and centrifuged at 11,500 x g for $20 \mathrm{~min}$ at $4^{\circ} \mathrm{C}$. Protease inhibitors (cat. no. 635673; Takara Bio, Inc.) were added to cell lysates. Cells were then placed on ice for $30 \mathrm{~min}$ until complete dissolution and the supernatant was transferred to a new EP tube. Total protein concentration was determined using a Pierce ${ }^{\mathrm{TM}}$ BCA Protein Assay kit (cat. no. 23227; Thermo Fisher Scientific, Inc.), according to the manufacturer's protocol. Proteins were separated via $12 \%$ SDS-PAGE (15 $\mu \mathrm{g}$ protein/gel lane) and transferred to PVDF membranes (EMD Millipore). Membranes were blocked with $5 \%$ skim milk for $1 \mathrm{~h}$ at $25^{\circ} \mathrm{C}$. Following this, primary antibodies were added and cells were incubated overnight at $4^{\circ} \mathrm{C}$. After washing with TBST, horseradish peroxidaseconjugated rabbit anti-mouse immunoglobulin $\mathrm{G}$ secondary antibodies (1:5,000; cat. no. 61-6520; Thermo Fisher Scientific, Inc.) was added and incubated for $1 \mathrm{~h}$ at room temperature. Proteins bands were detected using ECL ${ }^{\mathrm{TM}}$ Western Blotting Detection reagents (cat. no. RPN2209; Sigma-Aldrich; Merck $\mathrm{KGaA}$ ). Gray values of each protein bands were analyzed using ImageJ software (version 1.46; National Institute of Health). Additionally, the gray values obtained from each group were compared with the gray values of the corresponding $\beta$-actin band to analyze protein expression levels. The ratio of LC3-II/LC3-I were calculated based on gray values of LC3-II and LC3-I. Primary antibodies used were as follows: LC3 (1:1,000; cat. no. M152-3; Medical \& Biological Laboratories Co., Ltd.), Beclin-1 (1:1,000; cat. no. NB500-249; Novus Biologicals, Inc.), HIPK2 (1:1,000; cat.no. 5091; Cell Signaling Technology, Inc.) and $\beta$-actin (1:5,000; cat. no. 3700S; New England BioLabs, Inc.).

Ethical statement. All animal procedures were in accordance with the guidelines approved by the Institutional Animal Care and Use Committee of Third XiangYa Hospital of Central South University, Hunan, China (approval no. 2019-S534).

Statistical analysis. Statistical analysis was performed using SPSS software (version 19.0; IBM Corp.) and data are presented as mean \pm standard deviation. Differences between groups were analyzed using one-way or two-way ANOVA followed by Bonferroni's post hoc test, and unpaired Student's t-tests. All experiments were performed and analyzed in triplicate. $\mathrm{P}<0.05$ was considered to indicated a statistically significant difference.

\section{Results}

Expression levels of circ-016901, miR-1249-5p and HIPK2 are associated with irradiation in BMSCs. To investigate the effect of radiation on BMSCs, the effects of different doses $(2,4$ and $6 \mathrm{GY})$ of radiation on the proliferation of BMSCs was examined using CCK-8 assays. Compared with the control group, irradiation treatment significantly decreased the cell proliferation of BMSCs in a dose-dependent manner (Fig. 1A; $\mathrm{P}<0.01$ ). The mRNA and protein expression levels of autophagy-related genes (including Beclin-1 and LC3) were detected at various irradiation doses via RT-qPCR 

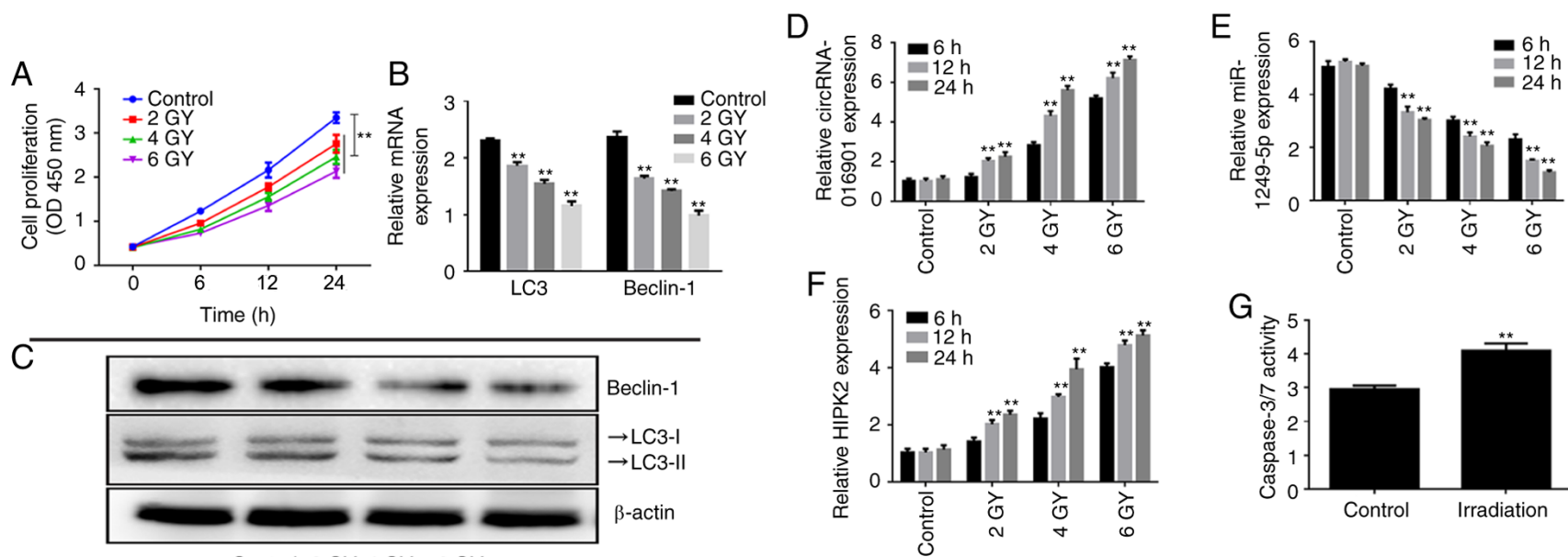

Control $2 \mathrm{GY} 4 \mathrm{GY} 6 \mathrm{GY}$
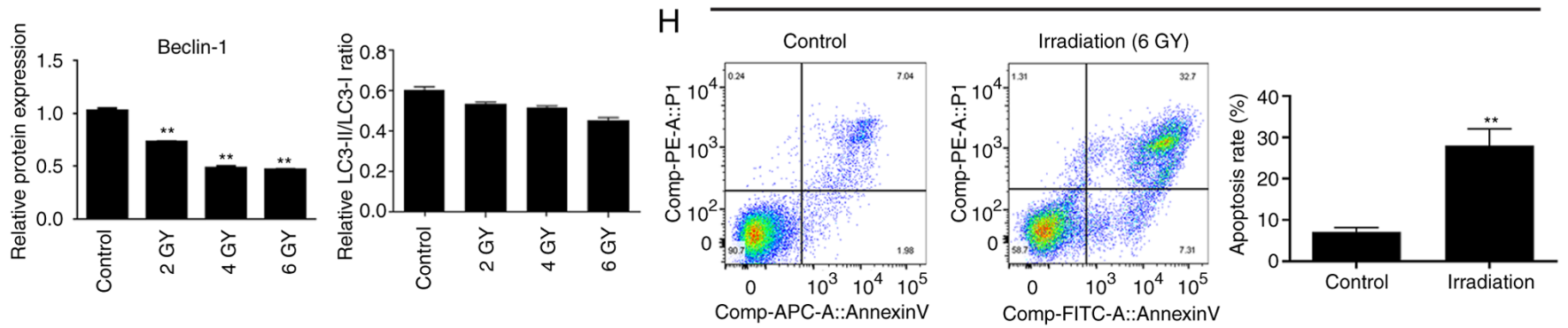

Figure 1. Expression levels of circ-016901, miR-1249-5p and HIPK2 are associated with irradiation in BMSCs. (A) Effect of various doses of irradiation on the proliferation of BMSCs was measured by using Cell Counting Kit-8 assays. (B) mRNA and (C) protein expression levels of Beclin-1 and LC3-II/I in BMSCs treated with various doses of irradiation were detected using RT-qPCR and western blotting, respectively. Expression levels of (D) circ-016901, (E) miR-1249-5p and (F) HIPK2 in BMSCs treated with various doses of irradiation were detected using RT-qPCR. Apoptosis rates of BMSCs treated with irradiation was detected using $(\mathrm{G})$ caspase-3/7 and $(\mathrm{H})$ flow cytometry. Data are presented as mean \pm standard deviation. Experiments were performed in triplicate. ${ }^{* *} \mathrm{P}<0.01$ vs. the control group. circ, circular RNA; miR, microRNA; HIPK2, homeodomain-interacting protein kinase; BMSC, bone marrow mesenchymal stem cells; LC3, light chain 3; RT-qPCR, reverse transcription-quantitative PCR; OD, optical density.

and western blotting, respectively. The results indicated that the mRNA and protein expression levels of Beclin-1 were significantly decreased in irradiation-treated BMSCs in a dose-dependent manner compared with the control group (Fig. 1B and $\mathrm{C} ; \mathrm{P}<0.01$ ). Additionally, although the mRNA expression of LC3 was significantly decreased, there was no significant difference in the ratio of LC3-II/LC3-I compared with the control group. Furthermore, irradiation treatment significantly upregulated circ-016901 and HIPK2 expression, and downregulated miR-1249-5p expression in a time- and dose-dependent manner in BMSCs compared with the control group (Fig. 1D-F; $\mathrm{P}<0.01$ ). Therefore, the $6 \mathrm{GY}$ dose and $24 \mathrm{~h}$ time point was used for all subsequent studies. Furthermore, the results indicated that irradiation treatment significantly increased caspase-3/7 activity (Fig. 1G) and increased apoptosis in BMSCs and (Fig. 1H; $\mathrm{P}<0.01$ ). The current results indicated that circ-016901, miR-1249-5p and HIPK2 had potential regulatory effects in irradiation-induced injury of BMSCs.

Silencing of circ-016901 attenuates cell injury induced by irradiation in BMSCs. BMSCs were transfected with circ-016901 siRNA or siNC prior to treatment with $6 \mathrm{GY}$ irradiation for $24 \mathrm{~h}$. Transfection efficiency was verified by using RT-qPCR and the results demonstrated that circ016901 siRNA significantly downregulated circ-016901 expression compared with the siNC group (Fig. $2 \mathrm{~A} ; \mathrm{P}<0.01$ ).
Furthermore, CCK-8 assays revealed that circ-016901 silencing significantly increased the proliferation of BMSCs treated with irradiation compared with the siNC group (Fig. 2B; $\mathrm{P}<0.05$. Circ-016901 siRNA significantly upregulated the mRNA and protein expression levels of Beclin-1 and LC3 II/I in irradiation-treated BMSCs compared with the siNC group (Fig. 2C-E; $\mathrm{P}<0.01$ ). Additionally, circ016901 silencing significantly inhibited the apoptosis of irradiation-treated BMSCs compared with the siNC group (Fig. 2F and $\mathrm{G}$; $\mathrm{P}<0.01$ ). Similar results were obtained from the measurement of caspase-3/7 activity (Fig. $2 \mathrm{H} ; \mathrm{P}<0.01$ ). These results demonstrated that circ-016901 siRNA promoted cell proliferation and autophagy, and inhibited apoptosis of irradiation-treated BMSCs, indicating that circ-016901 silencing attenuated the cell injury induced by irradiation of BMSCs.

circ-016901 regulates the miR-1249-5p/HIPK2 axis in irradiation-treated BMSCs. Bioinformatics analysis using the online Targetscan and Starbase databases revealed that miR-1249-5p had a binding site for circ-016901 (Fig. 3A and C) and the 3'-UTR of HIPK2 had a binding site for miR-1249-5p (Fig. 3B). To investigate whether circ-016901 regulated the miR-1249-5p/ HIPK 2 axis in irradiation-treated BMSCs, the expression levels of miR-1249-5p and HIPK2 in BMSCs transfected with circ-016901 siRNA were detected via RT-qPCR. The results demonstrated that circ-016901 silencing significantly upregu- 
A
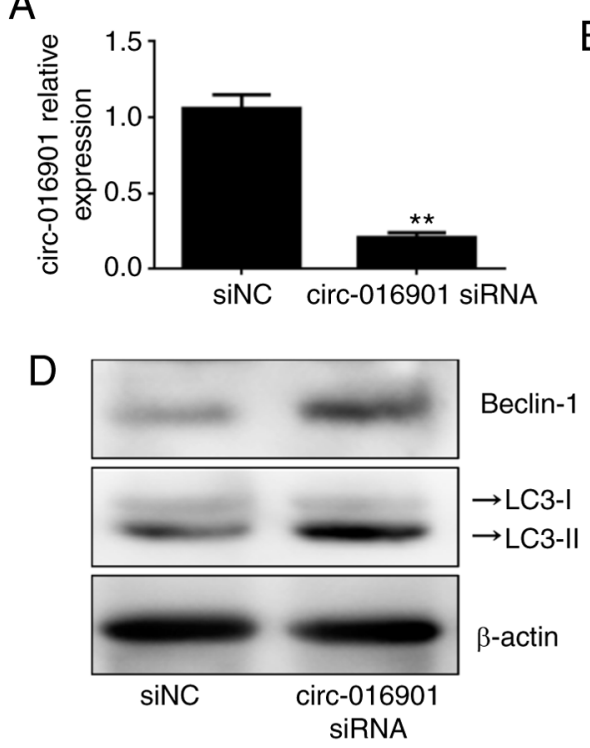

$\mathrm{F}$

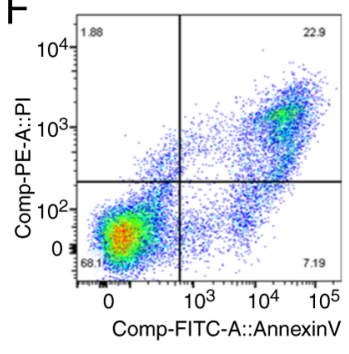

siNC
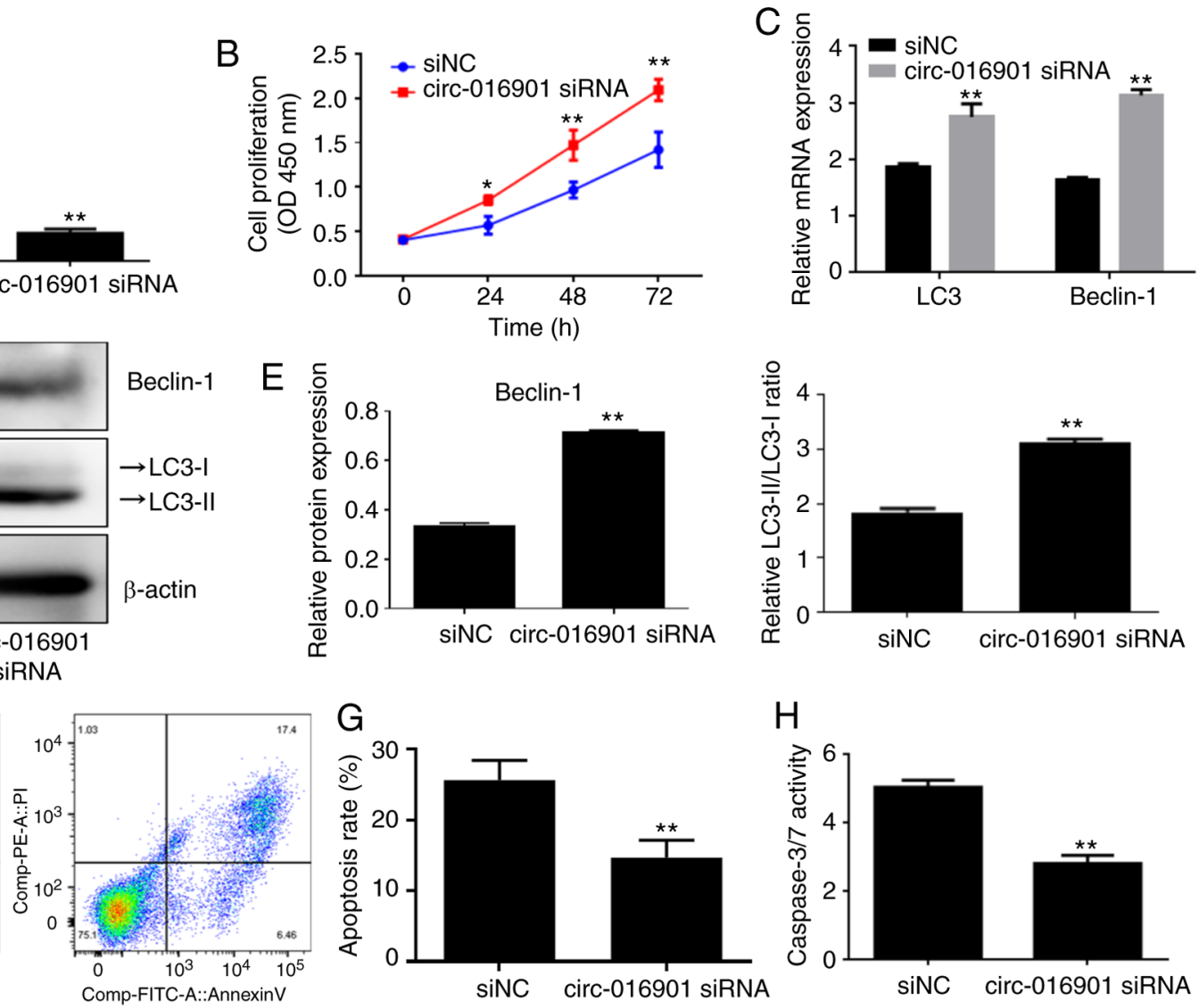

Figure 2. Silencing of circ-016901 attenuates cell injury induced by irradiation in BMSCs. (A) Transfection efficiency of circ-016901 silencing was detected via RT-qPCR. (B) Effect of circ-016901 silencing on the proliferation of irradiation-treated BMSCs was measured using Cell Counting Kit-8 assays. Effect of circ-016901 silencing on (C) mRNA and (D and E) protein expression levels of Beclin-1 and LC3-II/I in irradiation-treated BMSCs was examined using RT-qPCR and western blotting, respectively. Apoptosis rates of irradiation-induced BMSCs following transfection with circ-016901 siRNA was detected using ( $\mathrm{F}$ and $\mathrm{G}$ ) flow cytometry and $(\mathrm{H})$ caspase-3/7 activity. Data are presented as mean \pm standard deviation. Experiments were performed in triplicate. ${ }^{*} \mathrm{P}<0.05$ and $^{* *} \mathrm{P}<0.01$ vs. the siNC group. BMSCs, bone marrow mesenchymal stem cells; circ, circular; RT-qPCR, reverse transcription-quantitative PCR; LC3, light chain 3; si, small interfering; NC, negative control; OD, optical density.

lated the expression of miR-12249-5p (Fig. 3D; P<0.01) and downregulated HIPK2 expression (Fig. 3E; $\mathrm{P}<0.01$ ) compared with the siNC group. Additionally, western blotting analysis indicated that circ-016901 silencing decreased HIPK2 protein expression compared with the siNC group (Fig. 3F and G; $\mathrm{P}<0.01)$. Furthermore, the direct target association between miR-1249-5p, circ-016901 and HIPK2 was verified using luciferase reporter assays. The miR-1249-5p overexpression significantly decreased the relative luciferase activity of WT-circ-016901 (Fig. 3H) and WT-HIPK2 (Fig. 3I) compared with the control mimic group. However, there were no significant differences between MUT-circ-016901 and MUT-HIPK2 and control mimics following miR-1249-5p overexpression. These results indicated that circ-016901 regulates the expression of miR-1249-5p, and that miR-1249-5p directly modulates the expression of HIPK2 via binding the HIPK2 3'-UTR. These results suggested that the circ-016901/miR-1249-5p/HIPK2 axis may represent a regulatory signaling pathway involved in the irradiation-induced injury of BMSCs.

HIPK2 silencing mimics the effects of miR-1249-5p in irradiation-treated BMSCs. To explore the possible regulatory role of miR-1249-5p and HIPK2 in the
circ-016901/miR-1249-5p/HIPK2 axis in irradiation-treated BMSCs, miR-1249-5p mimics, HIPK2 siRNA and corresponding controls (control mimic and siNC, respectively) were transfected into BMSCs. miR-1249-5p mimics significantly downregulated HIPK2 expression at the mRNA (Fig. 4A) and protein levels (Fig. 4B) compared with the control mimic group $(\mathrm{P}<0.01)$. Furthermore, RT-qPCR was used to verify the transfection efficiency of miR-1249-5p overexpression and HIPK2 silencing. The results demonstrated that miR-1249-5p overexpression significantly increased miR-1249-5p expression (Fig. 4C; $\mathrm{P}<0.01$ ), while HIPK2 silencing decreased the expression of HIPK2 (Fig. 4D; P<0.01). Additionally, western blotting indicated that HIPK2 silencing decreased HIPK2 protein expression compared with the siNC group (Fig. 4E; $\mathrm{P}<0.01)$. CCK- 8 assays were used to determine the effect of miR-1249-5p and HIPK2 on the proliferation of irradiationtreated BMSCs and the results revealed that miR-1249-5p overexpression and HIPK2 silencing significantly promoted the proliferation of irradiation-treated BMSCs compared with their respective controls (Fig. 4F; P $<0.01$ ). Furthermore, miR-1249-5p mimics and HIPK2 siRNA efficiently inhibited the apoptosis of irradiation-treated BMSCs compared with the control mimic and siNC groups, respectively (Fig. 4G and H; 

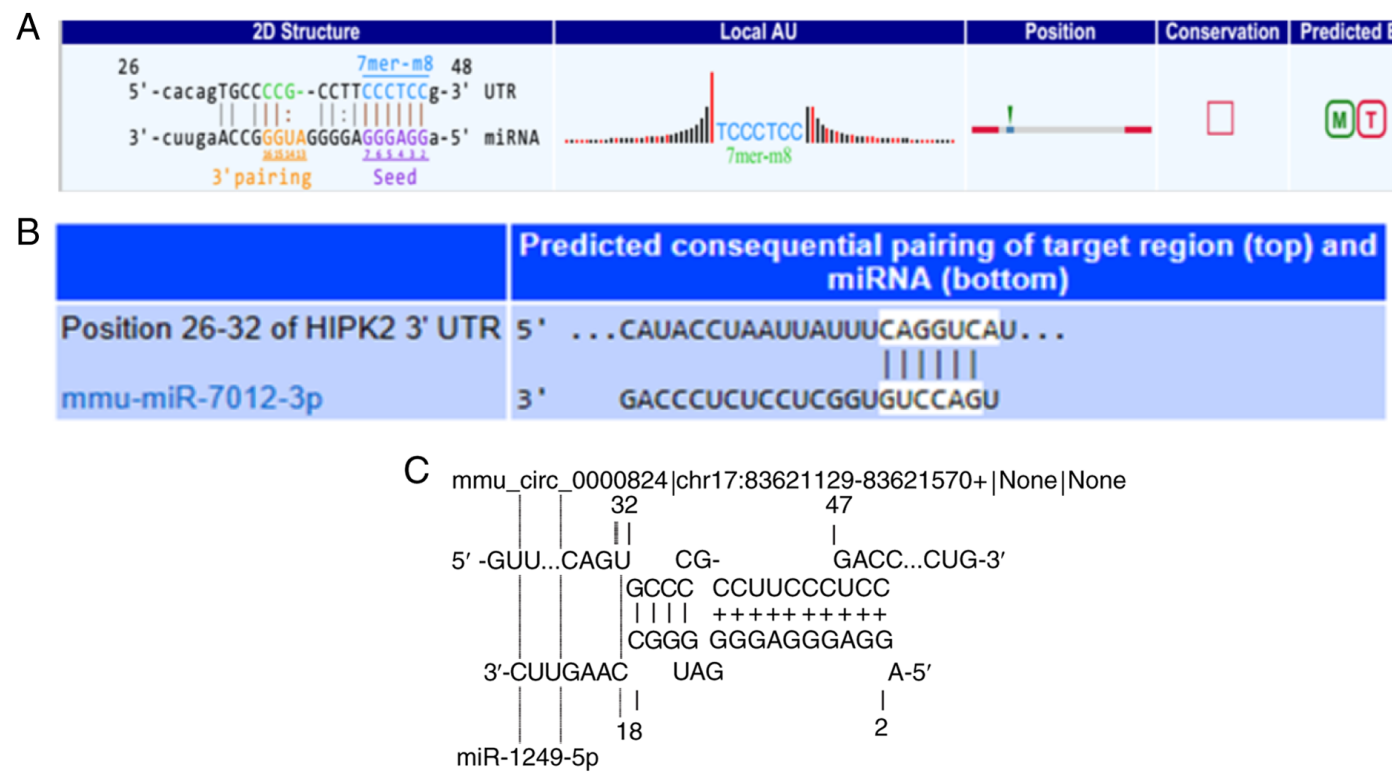

Interaction energy=-23.27 $\mathrm{kcal} / \mathrm{mol}$
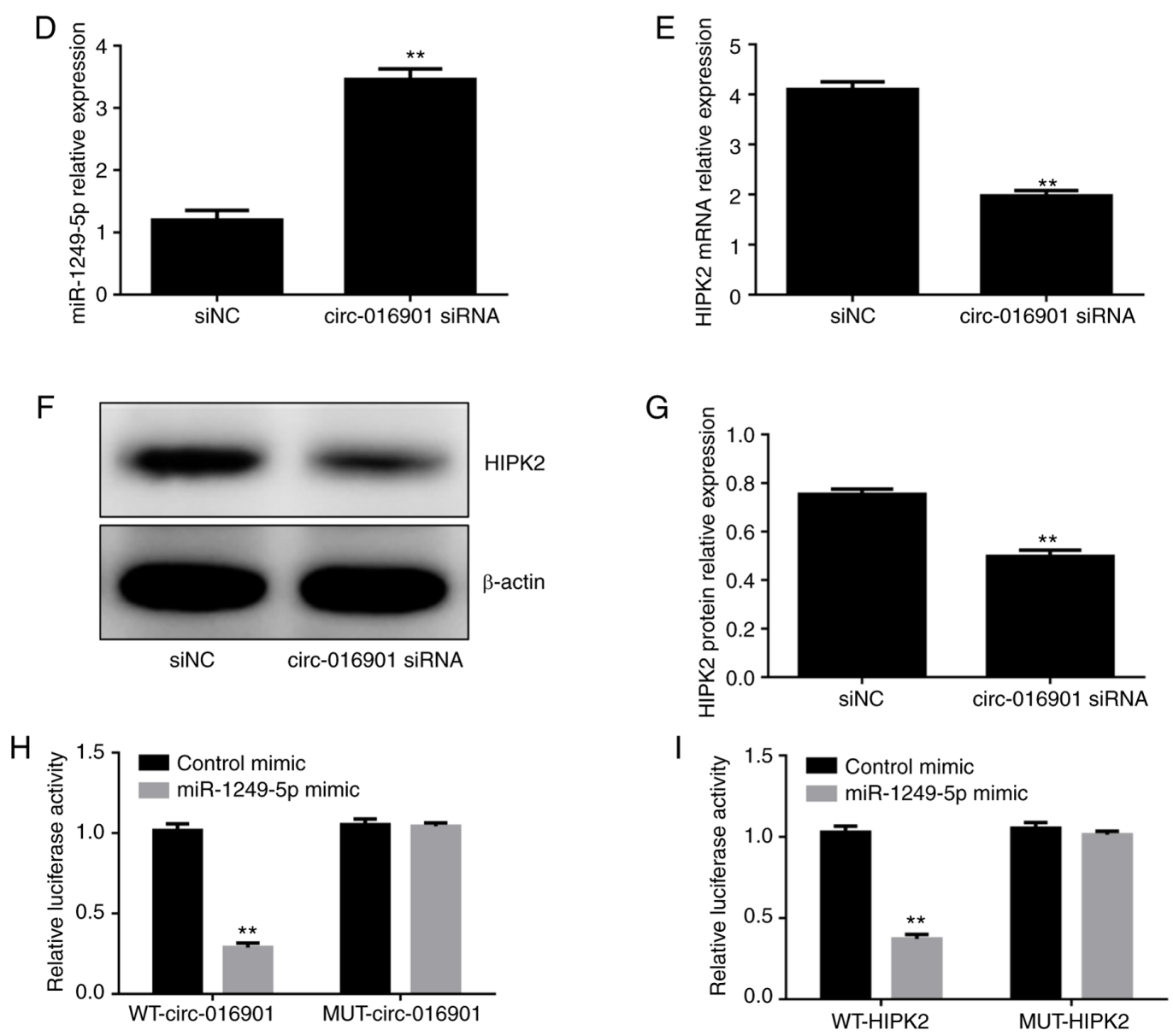

Figure 3. Circ-016901 regulates the miR-1249-5p/HIPK2 axis in irradiation-treated BMSCs. (A) Starbase predicted miR-1249-5p as a target for circ-016901. (B) TargetScan predicted HIPK2 as a target for miR-1249-5p. (C) IntaRNA predicted miR-1249-5p as a target for circ-016901. (D) Circ-016901 silencing upregulated miR-1249-5p expression. Circ-016901 silencing downregulated the (E) mRNA and (F and G) protein expression levels of HIPK2. (H) Luciferase reporter assays indicated that there was an interaction between circ-016901 and miR-1249-5p. (I) Luciferase reporter assays demonstrated that there was an interaction between HIPK2 and miR-1249-5p. Data are presented as mean \pm standard deviation. Experiments were performed in triplicate. ${ }^{* *} \mathrm{P}<0.01 \mathrm{vs}$. the siNC or control mimic groups. Circ, circular; miR, microRNA; HIPK2, HIPK2, homeodomain-interacting protein kinase; BMSCs, bone marrow mesenchymal stem cells; si, small interfering; NC, negative control; UTR, untranslated region; WT, wild-type; MUT, mutant.

$\mathrm{P}<0.01)$. RT-qPCR and western blotting results indicated that miR-1249-5p overexpression and HIPK2 silencing signifi- cantly increased the mRNA and protein expression levels of LC3 II/I and Beclin-1 compared with the control mimic 
A
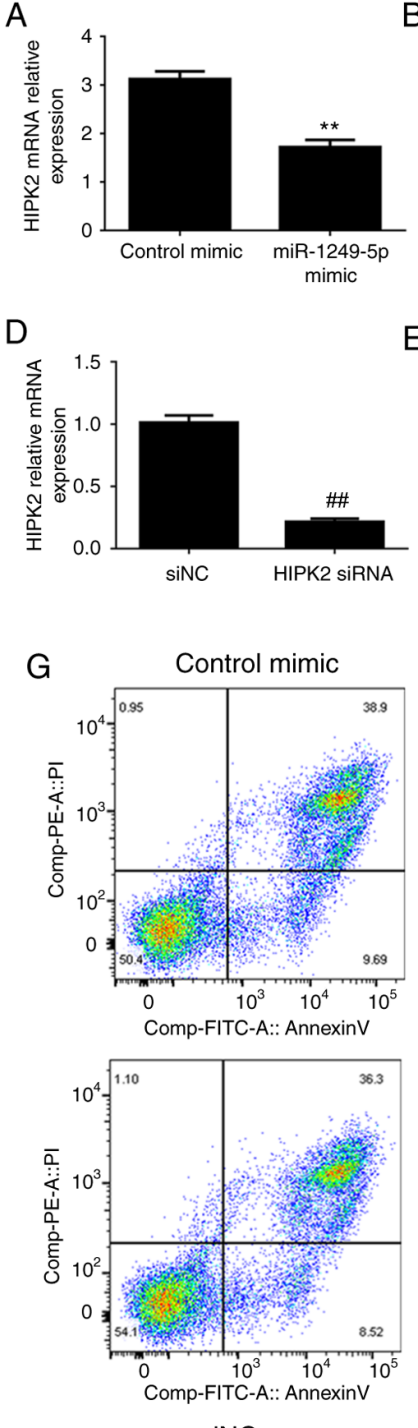

siNC

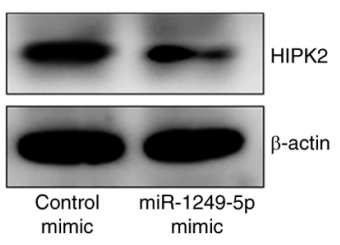

E

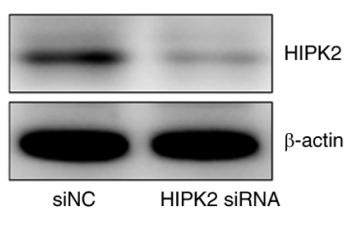

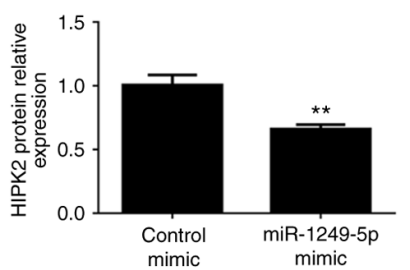

mimic
C
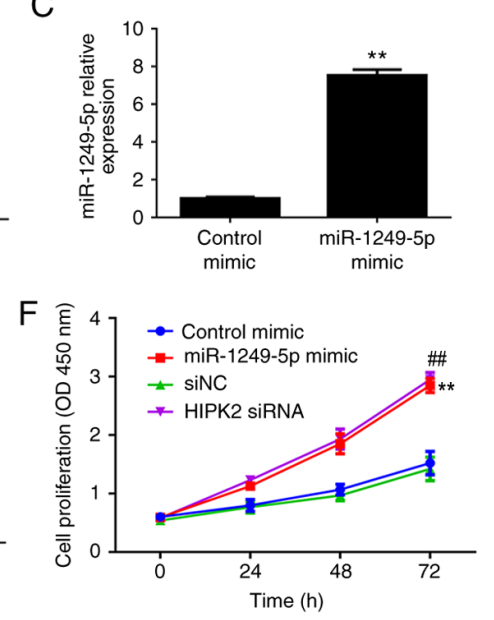
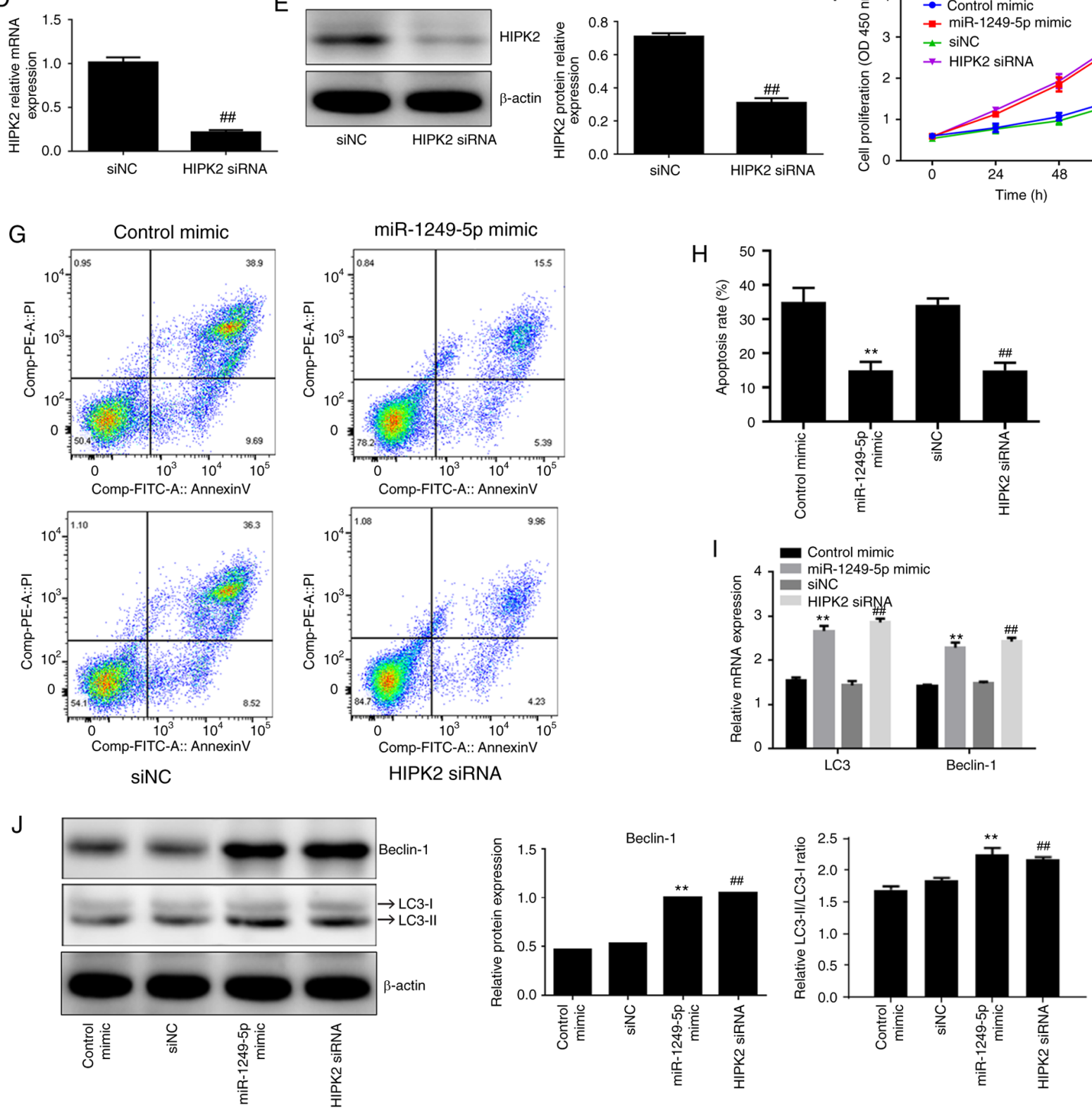

Figure 4. HIPK2 silencing mimics the effects of miR-1249-5p in irradiation-treated BMSCs. Effect of miR-1249-5p overexpression on the (A) mRNA and (B) protein expression levels of HIPK2 was detected using RT-qPCR and western blotting, respectively. (C) Transfection efficiency of miR-1249-5p overexpression was detected using RT-qPCR. Transfection efficiency of HIPK2 silencing on (D) mRNA and (E) protein expression levels was detected using RT-qPCR and western blotting. (F) Effect of miR-1249-5p overexpression and HIPK2 silencing on the proliferation of irradiation-treated BMSCs was measured using Cell Counting Kit-8 assays. ( $\mathrm{G}$ and H) Apoptosis rates of irradiation-induced BMSCs following transfection with circ-016901 siRNA was detected using flow cytometry. Effect of miR-1249-5p overexpression and HIPK2 silencing on the (I) mRNA and (J) protein expression levels of Beclin-1 and LC3-II/I in irradiation-treated BMSCs were detected using RT-qPCR and western blotting, respectively. Data are presented as mean \pm standard deviation. Experiments were performed in triplicate. ${ }^{* *} \mathrm{P}<0.01$ vs. the siNC, ${ }^{\sharp /} \mathrm{P}<0.01$ vs. the control mimic groups. HIPK2, homeodomain-interacting protein kinase; miR, microRNA; BMSCs, bone marrow mesenchymal stem cells; RT-qPCR, reverse transcription-quantitative PCR; circ, circular; si, small interfering; LC3, light chain 3; NC, negative control; OD, optical density.

and siNC groups (Fig. 4I and $\mathrm{J}$, respectively; $\mathrm{P}<0.05$ ), indicating that miR-1249-5p and HIPK2 promoted autophagy of irradiation-treated BMSCs. These results demonstrated that the miR-1249-5p/HIPK2 axis attenuated irradiation-induced injury of BMSCs by promoting proliferation and autophagy, and inhibiting apoptosis. 


\section{Discussion}

In the clinical treatment of hematological malignancies, allogeneic BM transplantations may be performed and TBI can be used to induce immunosuppression to eradicate malignant cells and prevent donor BM rejection (20). TBI-induced damage is associated with the type of irradiation, dose and time (58). The clinical choice of irradiation can result in BM ablation and a more severe degree of immunosuppression, which may induce treatment-related toxicity and poor therapeutic effects (20). Therefore, irradiation-induced damage on BM can be beneficial or harmful depending on the application process. A previous study has demonstrated that long-term BM suppression caused by irradiation is primarily dependent on residual hematopoietic stem cells and BMSCs for recovery (59). BMSCs have been reported to be involved in the repair process of tumor tissue following tumor resection (60) and tumor cells secrete a variety of chemokines, including CCL5 and CCL2 $(61,62)$ to recruit BMSCs. Furthermore, irradiation therapy on tumor tissues can cause damage to BMSCs in surrounding tumor tissues (63). The present study investigated the effect of radiation on mRNA and protein expression of autophagy-related genes and the results demonstrated that the mRNA and protein level of Beclin-1 were significantly decreased in a dose-dependent manner, which indicated that radiation may induce autophagy in BMSCs. Furthermore, LC3-II and LC3-I expression levels were reduced in response to irradiation; however, there was no significant difference between the LC3-II/ LC-I ratio. The mechanism underlying this phenomenon remains unknown. Further investigations are required to elucidate this mechanism. Additionally, the preseny study demonstrated that irradiation upregulated the expression of circ-016901 and HIPK2 in BMSCs and downregulated miR-1249-5p expression. Silencing of circ-016901 attenuated the injury in irradiation-induced BMSCs by regulating the miR-1249-5p/HIPK2 axis.

A recent study has reported that circ-016901 is upregulated in BMSCs treated with irradiation (34). However, to the best of our knowledge, no other studies have been reported concerning this novel circRNA. In the present study, irradiation treatment significantly increased the expression of circ-016901. Additionally, circ-016901 silencing promoted proliferation and autophagy, and inhibited apoptosis in irradiation-treated BMSCs. Previous studies have indicated that circRNAs serve as competing endogenous RNAs to adsorb miRNAs and regulate the expression of target gene mRNA $(64,65)$. Therefore, the current study focused on the competing endogenous mechanism of circ-016901 that is involved in radiation-induced injury of BMSCs. Online bioinformatics analysis indicated that miR-1249-5p was a connecting carrier for circ-016901 and HIPK2. Luciferase reporter assays further verified that circ-016901 and HIPK2 could bind miR-1249-5p in BMSCs. To investigate the role of miR-1249-5p in irradiation-treated BMSCs, miR-1249-5p functional assays were performed. The results demonstrated that miR-1249-5p overexpression significantly promoted proliferation and autophagy, and inhibited apoptosis; these results were similar to those obtained from circ-016901 silencing. Notably, a previous study on colorectal cancer cell lines reported that the protective role of miR-1249-5p was contradicted with the inhibitory effect of miR-1249 overexpression (43), while the positive regulatory role of miR-1249 on the proliferation in glioma cell line (66) was similar to the current results. These opposing regulatory functions of miR-1249 may be due to the complexity and differences in the physiological regulatory networks of different cell lines or physiological or pathological status.

Previous studies have demonstrated that HIPK2 may represent a potential tumor suppressor that inhibits tumor growth and enhance drug sensitivity via regulating certain key molecular pathways including p53-independent apoptosis pathways and the hypoxia inducible factor $1 \alpha$ (HIF-1 $\alpha)$ pathway in tumor cells $(67,68)$. Research has reported that HIPK 2 induces apoptosis in a dependent or non-dependent manner via the $\mathrm{p} 53$ gene (69). Phosphorylation at position 46 of p53 activates the expression of the negative regulator $\mathrm{p} 53$, thereby directing cells for DNA repair or apoptosis inhibition (53), while silencing HIPK2 reduces apoptosis (70). The current study revealed that miR-1249-5p overexpression significantly downregulated the expression of HIPK2. Furthermore, HIPK2 silencing promoted proliferation and autophagy, and inhibited apoptosis, which mimicked the protective effects of miR-1249-5p overexpression in irradiation-treated BMSCs. These results confirmed that the miR-1249-5p/HIPK2 axis is involved in circ-016901-mediated irradiation-induced injury of BMSCs. However, the effects of circRNA-016901 on certain important markers for osteoblast differentiation, including alkaline phosphatase (ALP), collaged 1 (ConI), osteocalcin (OCN), osteopontin (OPN) and Runt-related transcription factor 2 (RUNX2) were not examined. Therefore, further studies are required to reveal the role of circRNA-016901 in the regulation of these genes.

In summary, the present study demonstrated that circ-016901 attenuated injury in irradiation-induced mouse BMSCs via regulating the miR-1249-5p/HIPK2 axis. The circRNA-016901/miR-1249-5p/HIPK2 axis may serve a crucial role in protecting BMSCs from irradiation injury. These results indicated a novel regulatory mechanism for BMSC radiation stress and further elucidated the molecular mechanisms of radiobiological effects. Future studies involving the role of circRNA-016901 in the regulation of osteoblast differentiation markers (ALP, ConI, OCN, OPN and RUNX2) will be conducted to investigate an effective treatment for irradiation damage in BMSCs.

\section{Acknowledgements}

Not applicable.

\section{Funding}

The present study was supported by the Hunan Natural Science Foundation (grant no. 2018JJ3791), the National Natural Science Foundation of China (grant nos. 81602801 and 81573091), the Natural Science Foundation of Hunan Province (grant no. 2019JJ50909) and the Research Project of Hunan Health and Family Planning Commission (grant no. B2017100). 


\section{Availability of data and materials}

All data generated or analyzed during this study are included in this published article.

\section{Authors' contributions}

WY, RG and XN analyzed and interpreted the data. DS, RH and HD performed the experiments. XW wrote the manuscript and interpreted the data. JZ contributed to the study design. All authors read and approved the final manuscript.

\section{Ethics approval and consent to participate}

Animal studies were performed in accordance with the Declaration of Helsinki and approved by the institutional Ethics Committee of the Third Xiangya Hospital of Central South University, Hunan, China (approval no. 2019-S534).

\section{Patient consent for publication}

Not applicable.

\section{Competing interests}

The authors declare that they have no competing interests.

\section{References}

1. Berger JM, Singh P, Khrimian L, Morgan DA, Chowdhury S, Arteaga-Solis E, Horvath TL, Domingos AI, Marsland AL, Yadav VK, et al: Mediation of the Acute Stress Response by the Skeleton. Cell Metab 30: 890-902.e8, 2019

2. Hayashi M, Nakashima T, Yoshimura N, Okamoto K, Tanaka S and Takayanagi H: Autoregulation of osteocyte Sema3A orchestrates estrogen action and counteracts bone aging. Cell Metab 29: 627-637.e5, 2019.

3. Ren R, Ocampo A, Liu GH and Izpisua Belmonte JC: Regulation of stem cell aging by metabolism and epigenetics. Cell Metab 26 460-474, 2017

4. Fan Y, Hanai JI, Le PT, Bi R, Maridas D, DeMambro V, Figueroa CA, Kir S, Zhou X, Mannstadt M, et al: Parathyroid hormone directs bone marrow mesenchymal cell fate. Cell Metab 25: 661-672, 2017.

5. Stegen S, van Gastel N, Eelen G, Ghesquière B, D'Anna F, Thienpont B, Goveia J, Torrekens S, Van Looveren R, Luyten FP, et al: HIF-1 $\alpha$ promotes glutamine-mediated redox homeostasis and glycogen-dependent bioenergetics to support postimplantation Bone Cell Survival. Cell Metab 23: 265-279, 2016.

6. Li CJ, Xiao Y, Yang M, Su T, Sun X, Guo Q, Huang Y and Luo XH: Long noncoding RNA Bmncr regulates mesenchymal stem cell fate during skeletal aging. J Clin Invest 128: 5251-5266, 2018.

7. Li CJ, Cheng P, Liang MK, Chen YS, Lu Q, Wang JY, Xia ZY, Zhou HD, Cao X, Xie H, et al: MicroRNA-188 regulates agerelated switch between osteoblast and adipocyte differentiation. J Clin Invest 125: 1509-1522, 2015.

8. Yu Y, Newman H, Shen L, Sharma D, Hu G, Mirando AJ, Zhang H, Knudsen E, Zhang GF, Hilton MJ, et al: Glutamine metabolism regulates proliferation and lineage allocation in skeletal stem cells. Cell Metab 29: 966-978.e4, 2019.

9. Kode A, Mosialou I, Manavalan SJ, Rathinam CV, Friedman RA, Teruya-Feldstein J, Bhagat G, Berman E and Kousteni S: FoxO1dependent induction of acute myeloid leukemia by osteoblasts in mice. Leukemia 30: 1-13, 2016.

10. Raaijmakers MHGP, Mukherjee S, Guo S, Zhang S, Kobayashi T, Schoonmaker JA, Ebert BL, Al-Shahrour F, Hasserjian RP, Scadden EO, et al: Bone progenitor dysfunction induces myelodysplasia and secondary leukaemia. Nature 464: 852-857, 2010.

11. Guipaud O, Jaillet C, Clément-Colmou K, François A, Supiot S and Milliat F: The importance of the vascular endothelial barrier in the immune-inflammatory response induced by radiotherapy. Br J Radiol 91: 20170762-20170762, 2018.
12. Lee H,LiC,Zhang Y,Zhang D, Otterbein LEand Jin Y: Caveolin-1 selectively regulates microRNA sorting into microvesicles after noxious stimuli. J Exp Med 216: 2202-2220, 2019.

13. Singh PB, Pua HH, Happ HC, Schneider C, von Moltke J, Locksley RM, Baumjohann D and Ansel KM: MicroRNA regulation of type 2 innate lymphoid cell homeostasis and function in allergic inflammation. J Exp Med 214: 3627-3643, 2017.

14. Liu Y, Wang N, Zhang S and Liang Q: Autophagy protects bone marrow mesenchymal stem cells from palmitate-induced apoptosis through the ROS-JNK/p38 MAPK signaling pathways. Mol Med Rep 18: 1485-1494, 2018.

15. Brudno JN, Maric I, Hartman SD, Rose JJ, Wang M, Lam N, Stetler-Stevenson M, Salem D, Yuan C, Pavletic S, et al: T Cells genetically modified to express an anti-B-cell maturation antigen chimeric antigen receptor cause remissions of poor-prognosis relapsed multiple myeloma. J Clin Oncol 36: 2267-2280, 2018.

16. Turtle CJ, Hay KA, Hanafi LA, Li D, Cherian S, Chen X, Wood B, Lozanski A, Byrd JC, Heimfeld S, et al: Durable molecular remissions in chronic lymphocytic leukemia treated with CD19specific chimeric antigen receptor-modified $\mathrm{T}$ cells after failure of ibrutinib. J Clin Oncol 35: 3010-3020, 2017.

17. Zhang L, Yang F and Feng S: Allogeneic hematopoietic stem-cell transplantation for myelofibrosis. Ther Adv Hematol 11: 2040620720906002-2040620720906002, 2020.

18. García-García A, de Castillejo CL and Méndez-Ferrer S: BMSCs and hematopoiesis. Immunol Lett 168: 129-135, 2015.

19. Damek-Poprawa M, Stefanik D, Levin LM and Akintoye SO: Human bone marrow stromal cells display variable anatomic site-dependent response and recovery from irradiation. Arch Oral Biol 55: 358-364, 2010.

20. Paix A, Antoni D, Waissi W, Ledoux MP, Bilger K, Fornecker L and Noel G: Total body irradiation in allogeneic bone marrow transplantation conditioning regimens: A review. Crit Rev Oncol Hematol 123: 138-148, 2018.

21. Lucas D: The bone marrow microenvironment for hematopoietic stem cells. Adv Exp Med Biol 1041: 5-18, 2017.

22. Le Y, Fraineau S, Chandran P, Sabloff M, Brand M, Lavoie JR, Gagne R, Rosu-Myles M, Yauk CL, Richardson RB, et al: Adipogenic mesenchymal stromal cells from bone marrow and their hematopoietic supportive role: Towards understanding the permissive marrow microenvironment in acute myeloid leukemia. Stem Cell Rev Rep 12: 235-244, 2016.

23. Liu Z, Zhang Y, Xiao H, Yao Z, Zhang H, Liu Q, Wu B, Nie D, Li Y, Pang Y, et al: Cotransplantation of bone marrow-derived mesenchymal stem cells in haploidentical hematopoietic stem cell transplantation in patients with severe aplastic anemia: An interim summary for a multicenter phase II trial results. Bone Marrow Transplant 52: 704-710, 2017.

24. Rieger K, Marinets O, Fietz T, Körper S, Sommer D, Mücke C, Reufi B, Blau WI, Thiel E and Knauf WU: Mesenchymal stem cells remain of host origin even a long time after allogeneic peripheral blood stem cell or bone marrow transplantation. Exp Hematol 33: 605-611, 2005.

25. Wu KH, Wu HP, Chan CK, Hwang SM, Peng CT and Chao YH: The role of mesenchymal stem cells in hematopoietic stem cell transplantation: From bench to bedsides. Cell Transplant 22: 723-729, 2013.

26. Herberg S, Shi X, Johnson MH, Hamrick MW, Isales CM and Hill WD: Stromal cell-derived factor-1 $\beta$ mediates cell survival through enhancing autophagy in bone marrow-derived mesenchymal stem cells. PLoS One 8: e58207, 2013.

27. François S, Bensidhoum M, Mouiseddine M, Mazurier C, Allenet B, Semont A, Frick J, Saché A, Bouchet S, Thierry D, et al: Local irradiation not only induces homing of human mesenchymal stem cells at exposed sites but promotes their widespread engraftment to multiple organs: A study of their quantitative distribution after irradiation damage. Stem Cells 24: 1020-1029, 2006.

28. Mouiseddine M, François S, Semont A, Sache A, Allenet B, Mathieu N, Frick J, Thierry D and Chapel A: Human mesenchymal stem cells home specifically to radiation-injured tissues in a non-obese diabetes/severe combined immunodeficiency mouse model. Br J Radiol 80: S49-S55, 2007.

29. Herberg S, Kondrikova G, Hussein KA, PeriyasamyThandavan S, Johnson MH, Elsalanty ME, Shi X, Hamrick MW, Isales CM and Hill WD: Total body irradiation is permissive for mesenchymal stem cell-mediated new bone formation following local transplantation. Tissue Eng Part A 20: 3212-3227, 2014. 
30. Jeck WR, Sorrentino JA, Wang K, Slevin MK, Burd CE, Liu J, Marzluff WF and Sharpless NE: Circular RNAs are abundant, conserved, and associated with ALU repeats. RNA 19: 141-157, 2013.

31. Floris G, Zhang L, Follesa P and Sun T: Regulatory role of circular RNAs and neurological disorders. Mol Neurobiol 54: 5156-5165, 2017

32. Jiang G, Ma Y, An T, Pan Y, Mo F, Zhao D, Liu Y, Miao JN, $\mathrm{Gu}$ YJ, Wang Y, et al: Relationships of circular RNA with diabetes and depression. Sci Rep 7: 7285, 2017.

33. Meng S, Zhou H, Feng Z, Xu Z, Tang Y, Li P and Wu M: CircRNA: Functions and properties of a novel potential biomarker for cancer. Mol Cancer 16: 94, 2017.

34. Zhang J, Jiang J, Huang R, Wang Y, Nie X and Gui R: Circular RNA expression profiles are significantly altered in mice bone marrow stromal cells after total body irradiation. Leuk Res 70 : 67-73, 2018.

35. Balaga O, Friedman Y and Linial M: Toward a combinatorial nature of microRNA regulation in human cells. Nucleic Acids Res 40: 9404-9416, 2012.

36. Mousavi SR, Ahmadi A, Jamalkandi SA and Salimian J: Involvement of microRNAs in physiological and pathological processes in asthma. J Cell Physiol 234: 21547-21559, 2019.

37. Danka Mohammed CP, Park JS, Nam HG and Kim K: MicroRNAs in brain aging. Mech Ageing Dev 168: 3-9, 2017.

38. Ni J, Bucci J, Chang L, Malouf D, Graham P and Li Y: Targeting MicroRNAs in prostate cancer radiotherapy. Theranostics 7: 3243-3259, 2017

39. Bartel DP: MicroRNAs: Target recognition and regulatory functions. Cell 136: 215-233, 2009.

40. Lai EC: Micro RNAs are complementary to 3' UTR sequence motifs that mediate negative post-transcriptional regulation. Nat Genet 30: 363-364, 2002.

41. Sayed D and Abdellatif M: MicroRNAs in development and disease. Physiol Rev 91: 827-887, 2011.

42. Liu KX, Chen GP, Lin PL, Huang JC, Lin X, Qi JC and Lin QC: Detection and analysis of apoptosis- and autophagy-related miRNAs of mouse vascular endothelial cells in chronic intermittent hypoxia model. Life Sci 193: 194-199, 2018.

43. Chen X, Zeng K, Xu M, Liu X, Hu X, Xu T, He B, Pan Y, Sun H and Wang S: P53-induced miR-1249 inhibits tumor growth, metastasis, and angiogenesis by targeting VEGFA and HMGA2. Cell Death Dis 10: 131, 2019.

44. Yan L, Li J, Wu Q and Chen L: Specific miRNA expression profile in the blood serum of cardiac myxoma patients. Oncol Lett 16: 4235-4242, 2018

45. Yoshii S, Hayashi Y, Iijima H, Inoue T, Kimura K, Sakatani A, Nagai K, Fujinaga T, Hiyama S, Kodama T, et al: Exosomal microRNAs derived from colon cancer cells promote tumor progression by suppressing fibroblast TP53 expression. Cancer Sci 110: 2396-2407, 2019.

46. Seshachalam VP, Sekar K and Hui KM: Insights into the etiology-associated gene regulatory networks in hepatocellular carcinoma from The Cancer Genome Atlas. J Gastroenterol Hepatol 33: 2037-2047, 2018

47. Kulcheski FR, Christoff AP and Margis R: Circular RNAs are miRNA sponges and can be used as a new class of biomarker. J Biotechnol 238: 42-51, 2016.

48. Rodriguez-Gil A, Ritter O, Hornung J, Stekman H, Krüger M, Braun T, Kremmer E, Kracht M and Schmitz ML: HIPK family kinases bind and regulate the function of the CCR4-NOT complex. Mol Biol Cell 27: 1969-1980, 2016.

49. Kuwano Y, Nishida K, Akaike Y, Kurokawa K, Nishikawa T, Masuda $\mathrm{K}$ and Rokutan K: Homeodomain-interacting protein kinase-2: A Critical regulator of the DNA damage response and the epigenome. Int J Mol Sci 17: 1638, 2016.

50. Hashimoto K and Tsuji Y: Arsenic-induced activation of the homeodomain-interacting protein kinase 2 (HIPK2) to cAMPresponse element binding protein (CREB) Axis. J Mol Biol 429: 64-78, 2017.

51. Kwon MJ, Min SK, Seo J, Kim DH, Sung CO, Lim MS, Cho J and Park HR: HIPK 2 expression in progression of cutaneous epithelial neoplasm. Int J Dermatol 54: 347-354, 2015.

52. Zhang Z, Wen P, Li F, Yao C, Wang T, Liang B, Yang Q, Ma L and He L: HIPK2 inhibits cell metastasis and improves chemosensitivity in esophageal squamous cell carcinoma. Exp Ther Med 15: 1113-1118, 2018.

53. Fan Y, Wang N, Chuang P and He JC: Role of HIPK2 in kidney fibrosis. Kidney Int Suppl 2011 4: 97-101, 2014.
54. D'Orazi G, Cecchinelli B, Bruno T, Manni I, Higashimoto Y, Saito S, Gostissa M, Coen S, Marchetti A, Del Sal G, et al: Homeodomain-interacting protein kinase-2 phosphorylates p53 at Ser 46 and mediates apoptosis. Nat Cell Biol 4: 11-19, 2002.

55. Moffitt AD, Brignolo LL, Ardeshir A and Creamer-Hente MA The role of emotional contagion in the distress exhibited by grouped mice exposed to $\mathrm{CO}_{2}$. J Am Assoc Lab Anim Sci 58: 430-437, 2019.

56. Dominici M, Le Blanc K, Mueller I, Slaper-Cortenbach I, Marini F, Krause D, Deans R, Keating A, Prockop Dj and Horwitz E: Minimal criteria for defining multipotent mesenchymal stromal cells. The International Society for Cellular Therapy position statement. Cytotherapy 8: 315-317, 2006.

57. Wagner EM: Monitoring gene expression: Quantitative real-time rt-PCR. Methods Mol Biol 1027: 19-45, 2013

58. Wilke C, Holtan SG, Sharkey L, DeFor T, Arora M, Premakanthan P, Yohe S, Vagge S, Zhou D, Holter Chakrabarty JL, et al: Marrow damage and hematopoietic recovery following allogeneic bone marrow transplantation for acute leukemias: Effect of radiation dose and conditioning regimen. Radiother Oncol 118: 65-71, 2016

59. Zhou J, Pang H, Li W, Liu Q, Xu L, Liu Q and Liu Y: Effects of Lycium barbarum polysaccharides on apoptosis, cellular adhesion, and oxidative damage in bone marrow mononuclear cells of mice exposed to ionizing radiation injury. BioMed Res Int 2016: 1-8, 2016.

60. Hang HL and Xia Q: Role of BMSCs in liver regeneration and metastasis after hepatectomy. World J Gastroenterol 20: 126-132, 2014.

61. Li Y, Zheng Y, Li T, Wang Q, Qian J, Lu Y, Zhang M, Bi E, Yang M, Reu F, et al: Chemokines CCL2, 3, 14 stimulate macrophage bone marrow homing, proliferation, and polarization in multiple myeloma. Oncotarget 6: 24218-24229, 2015.

62. Chen R, Lee WY-W, Zhang XH, Zhang JT, Lin S, Xu LL, Huang B, Yang FY, Liu HL, Wang B, et al: Epigenetic modification of the CCL5/CCR1/ERK Axis enhances glioma targeting in dedifferentiation-reprogrammed BMSCs. Stem Cell Reports 8: 743-757, 2017.

63. Zhang J, Qiu X, Xi K, Hu W, Pei H, Nie J, Wang Z, Ding J, Shang $\mathrm{P}, \mathrm{Li} \mathrm{B}$, et al: Therapeutic ionizing radiation induced bone loss: A review of in vivo and in vitro findings. Connect Tissue Res 59: 509-522, 2018

64. Rong D, Sun H, Li Z, Liu S, Dong C, Fu K, Tang W and Cao H: An emerging function of circRNA-miRNAs-mRNA axis in human diseases. Oncotarget 8: 73271-73281, 2017.

65. Li G, Huang M, Cai Y, Yang Y, Sun X and Ke Y: Circ-U2AF1 promotes human glioma via derepressing neuro-oncological ventral antigen 2 by sponging hsa-miR-7-5p. J Cell Physiol 234: 9144-9155, 2019.

66. Fang B, Li G, Xu C, Hui Y and Li G: MicroRNA miR-1249 downregulates adenomatous polyposis coli 2 expression and promotes glioma cells proliferation. Am J Transl Res 10: 1324-1336, 2018

67. Lee S, Shang Y, Redmond SA, Urisman A, Tang AA, Li KH, Burlingame AL, Pak RA, Jovičić A, Gitler AD, et al: Activation of HIPK 2 promotes ER stress-mediated neurodegeneration in amyotrophic lateral sclerosis. Neuron 91: 41-55, 2016.

68. Lin J, Zhang Q, Lu Y, Xue W, Xu Y, Zhu Y and Hu X: Downregulation of HIPK2 increases resistance of bladder cancer cell to cisplatin by regulating Wip1. PLoS One 9: e98418, 2014.

69. Mancini F, Pieroni L, Monteleone V, Lucà R, Fici L, Luca E Urbani A, Xiong S, Soddu S, Masetti R, et al: MDM4/HIPK2/ p53 cytoplasmic assembly uncovers coordinated repression of molecules with anti-apoptotic activity during early DNA damage response. Oncogene 35: 228-240, 2016.

70. Zhao YX, Zhang GY, Wang AY, Chen YH, Lin DM and Li QF Role of homeodomain-interacting protein kinase 2 in the pathogenesis of tissue fibrosis in keloid-derived keratinocytes. Ann Plast Surg 79: 546-551, 2017.

This work is licensed under a Creative Commons Attribution-NonCommercial-NoDerivatives 4.0 International (CC BY-NC-ND 4.0) License. 